\title{
Management of Degenerative Spondylolisthesis: Analysis of a Questionnaire Study, Correlation With a National Sample, and Perioperative Outcomes of Treatment Options
}

PATAWUT BOVONRATWET, BS, ${ }^{1}$ MATTHEW L. WEBB, MD,${ }^{2}$ NATHANIEL T. ONDECK, BS, ${ }^{1}$ JONATHAN J. CUI, BS, ${ }^{1}$ RYAN P. MCLYNN, BS, ${ }^{1}$ PRAVEEN KADIMCHERLA, MD,${ }^{3}$ DAVID H. KIM, MD,${ }^{4}$ JONATHAN N. GRAUER, MD ${ }^{1}$

${ }^{1}$ Department of Orthopaedics and Rehabilitation, Yale School of Medicine, New Haven, Connecticut, ${ }^{2}$ Department of Orthopaedic Surgery, Hospital of the University of Pennsylvania, Philadelphia, Pennsylvania, ${ }^{3}$ Atlantic Spine Center, West Orange, New Jersey, ${ }^{4}$ Department of Orthopedic Surgery, New England Baptist Hospital, Boston, Massachusetts

\begin{abstract}
Background: Surgical treatment for lumbar degenerative spondylolisthesis has been shown to provide better longterm outcomes than conservative treatment. However, there is variation in surgical approaches employed by surgeons. This study investigates current surgical practice patterns and compares perioperative outcomes of 3 common surgical treatments for this pathology.

Methods: A survey was administered to surgeons who attended the Lumbar Spine Research Society (LSRS) meeting in 2014. Data were extracted from the American College of Surgeons National Surgical Quality Improvement Program (ACS-NSQIP) from 2005 to 2014 to characterize the same responses. The 2 data sets were compared. Perioperative outcomes of those in the ACS-NSQIP posterior fusion subcohorts were characterized and compared.

Results: Posterior surgical approaches utilized by surgeons who responded to the LSRS survey were similar to those captured by ACS-NSQIP where $72 \%$ of those with degenerative spondylolisthesis were fused. Of those that were fused, $8 \%$ had an uninstrumented posterior fusion, $33 \%$ had an instrumented posterior fusion, and $59 \%$ had an instrumented posterior fusion with interbody. On multivariate analysis, there was no difference in risk of postoperative adverse events, readmission, or length of stay between these 3 common types of fusion.

Conclusions: Practice patterns for the posterior management of lumbar degenerative spondylolisthesis were similar between LSRS survey responses and ACS-NSQIP data. The ACS-NSQIP perioperative outcome measures assessed were similar regardless of surgical technique. These findings highlight that cost-benefit considerations and longer-term outcomes have to be the measures by which surgical technique is chosen for degenerative spondylolisthesis.
\end{abstract}

Lumbar Spine

Keywords: lumbar degenerative spondylolisthesis, Lumbar Spine Research Society, survey, posterior fusion, complications, perioperative outcomes

\section{INTRODUCTION}

Lumbar degenerative spondylolisthesis with resultant stenosis is a common condition typically seen at L4-L5, in females more commonly than males, and in individuals older than 50 years of age. ${ }^{1,2}$ The slippage is generally due to degenerative changes in the zygapophyseal joints between the 2 vertebrae with accompanying degeneration of the disc at that level. ${ }^{3,4}$ Although conservative treatments are generally tried, surgery is often appropriately considered in the management of this condition if symptoms warrant. ${ }^{1,4}$

The benefits of surgery were verified by the Spine Patient Outcomes Research Trial (SPORT), which compared the effectiveness of surgical and nonsurgical treatment among participants with confirmed diagnoses of lumbar degenerative spondylolisthesis. Patients who were treated surgically showed substantially greater improvement in pain and functional status at 2 and 4 years follow-up. ${ }^{5-7}$

Although decompression is the primary surgical intervention for stenosis, fusion is generally considered in the setting of spondylolisthesis. This approach dates back to the seminal papers of Herkowitz and Fishgrund. ${ }^{8,9}$ If performing fusion, instrumentation has been accepted as a way to increase fusion success. ${ }^{9,10}$ Interbody techniques have been suggested as ways to increase fusion success, potentially improve alignment, and/or 
allow for grafting with minimally invasive techniques. ${ }^{10}$

However, there is debate on which fusion technique is best. Arguments for uninstrumented fusion include similar long-term results with and without instrumentation, poor cost-effectiveness of instrumentation, and risk of implant-related issues. ${ }^{11,12}$ Arguments for instrumented fusion include increasing fusion success and decreasing the rate of pseudarthrosis, a condition that leads to inferior long-term outcomes. ${ }^{1,13}$ The long-term advantages for instrumented posterior fusion with interbody are also inconclusive, largely from a lack of cost-benefit evidence. ${ }^{4,14,15}$

The goals of the current study are first to gauge current surgical practice trends for lumbar degenerative spondylolisthesis in a group of spine surgeons who attend the Lumbar Spine Research Society (LSRS) annual meetings and compare them to national trends from data available via the American College of Surgeons National Surgical Quality Improvement Program (ACS-NSQIP) database. The second goal is to compare short-term perioperative outcomes for patients who underwent common posterior-based approaches for this pathology: uninstrumented posterior fusion, instrumented posterior fusion, and instrumented posterior fusion with interbody. We hypothesized that there would be no clinically significant differences in perioperative outcomes between the 3 common surgical treatments.

\section{MATERIALS AND METHODS}

\section{Data Sources}

The LSRS was founded in 2008 and is affiliated with other spine societies such as AOSpine North America, Cervical Spine Research Society, and Scoliosis Research Society through membership in the Council of Surgical Spine Societies. The mission of the LSRS is to fill the need for a scientific gathering focused on the surgical treatment of the lumbar spine. The society accomplishes this by maintaining an academic annual meeting with no corporate funding, which offers an opportunity for research presentations followed by discussion amongst spine surgeons. ${ }^{16}$

The ACS-NSQIP database has been collecting chart-abstracted data from over 500 participating institutions in the United States since 2005. ${ }^{17}$ The database employs trained clinical reviewers to abstract over 150 specifically defined variables including preoperative comorbidities, intraoperative variables, and postoperative adverse outcomes through the 30th postoperative day regardless of hospital discharge. ${ }^{18}$ This data set has proved to be a valid data source in orthopedic surgery literature. ${ }^{19}$ The current study was found to be exempted from review by the Human Investigation Committee at our institution. The level of evidence in this study is Level III.

\section{Comparison of LSRS Survey and ACS-NSQIP Practice Patterns}

A survey was designed and circulated to spine surgeons who attended the LSRS annual meeting held in April 2014. A part of the survey, from which data were drawn for the current study, is included in the appendix. Data were then analyzed to determine common practices used for treatment of patients with degenerative spondylolisthesis (primary, nonrevision, single level).

The same cohort of patients referred to in the survey handed out at LSRS was selected from the ACS-NSQIP database (2005-2014) using the International Classification of Disease 9th Revision (ICD-9) code for spondylolisthesis (738.4). Singlelevel cases and posterior approaches were isolated by current procedural terminology (CPT) codes. Multiple-level cases, anterior, and lateral approaches were excluded. If the surgeons who attended the LSRS meeting are practicing in a hospital that feeds data to the NSQIP database, then their practice patterns may also be recorded in the NSQIP database. We did not attempt to determine whether or not the 2 data sources were overlapping or mutually exclusive since we believe the large difference in number of data points between the 2 sources would wash out any biases from any small overlaps.

This ACS-NSQIP cohort of patients was further separated using CPT codes into subsets that underwent decompression, posterior fusion, instrumented posterior fusion, and instrumented posterior fusion with interbody. Instrumented posterior fusion with interbody was treated as a subset of instrumented posterior fusion. Instrumented posterior fusion was in turn treated as a subset of posterior fusion.

Cases in which local autograft was solely used, iliac crest autograft was harvested, or bone marrow was aspirated, were also made into distinct groups. 
The ACS-NSQIP extracted data were then analyzed and compared to the survey data to determine if the national common practices used to treat patients with spondylolisthesis matched common practices utilized by LSRS surgeons.

\section{Analysis of Perioperative Outcomes of the ACS- NSQIP Population}

Further analysis was performed on 3 distinct groups of patients identified above: patients who underwent uninstrumented posterior fusion, instrumented posterior fusion, and instrumented posterior fusion with interbody. In this analysis, the 3 techniques are treated not as subsets of each other but as distinct groups. Patients who received only fusions and no decompression or who had a diagnosis other than degenerative spondylolisthesis were excluded. Anterior or lateral approaches were not included in the analysis, as that was not the population evaluated by the initial LSRS questionnaire and not the focus of this study.

Age, gender functional status prior to injury, and other comorbidities are directly reported in the ACS-NSQIP database. For each case, a modified version of the Charlson Comorbidity Index $(\mathrm{CCI})^{20}$ that has been adapted to the ACS-NSQIP database was calculated. $^{21}$ Several studies have shown that modified CCIs predict similar prognoses as the original CCI. ${ }^{22,23}$ Modified CCIs has also been previously used with ACS-NSQIP Data. ${ }^{24,25}$

The ACS-NSQIP database tracks patients for individual adverse events during the first 30 postoperative days. ${ }^{17}$ These events were used to generate 3 categories of adverse event outcomes as previously defined. ${ }^{26}$ The occurrence of a minor adverse event (MAE) was defined as the occurrence of any of the following: urinary tract infection, pneumonia, blood transfusion, readmission to hospital, wound dehiscence, deep vein thrombosis, superficial surgical site infection, deep surgical site infection, organ/space surgical site infection, sepsis without shock, return to the operating room, progressive renal insufficiency, unplanned intubation, and failure to wean from ventilation. The occurrence of a serious adverse event (SAE) was defined as the occurrence of any of the following: death, pulmonary embolism, acute renal failure, myocardial infarction, septic shock, stroke, and cardiac arrest requiring CPR. As there is some subjectiveness to the characterization of MAEs versus SAEs, the occurrence of any adverse event
(AAE) was also evaluated (defined as the occurrence of any of the MAEs or SAEs listed above).

Operative time (time from incision to closure), postoperative length of stay (LOS), and readmission were also directly reported in the ACS-NSQIP database. LOS is one of the few postoperative variables in the database that is reported beyond 30 days. In order to limit the influence of outliers on data analysis, any postoperative LOS that is longer than 30 days was coded as a LOS equal to 30 days instead. Occurrence of readmission within 30 days is reported in the ACS-NSQIP database for cases that occurred in 2011-2014 but not for earlier cases.

\section{Statistical Methods}

Statistical analyses were conducted using Stata version 13.0 (StataCorp, LP, College Station, Texas). Pearson's $\chi^{2}$ tests were used to compare patients who underwent uninstrumented posterior fusion, instrumented posterior fusion, and instrumented posterior fusion with interbody by age, gender, functional status prior to injury, and modified CCI. Unpaired $T$-tests with unequal variances were used to compare these 3 techniques by operative time and LOS. Pearson's $\chi^{2}$ tests and $T$-tests were conducted using a level of significance of $\alpha=0.05$.

Poisson regressions with robust error variance were used to calculate the relative risks of MAEs, SAEs, AAEs, and readmission. ${ }^{27}$ A Bonferroni correction $(n=4)$ was used, and a level of significance was set at $\alpha=0.0125$. $^{28}$

\section{RESULTS}

\section{Comparison of LSRS Survey and ACS-NSQIP Practice Patterns}

For the LSRS questionnaire, there was a response rate of 37 out of $61(60.7 \%)$. The responses were then analyzed and the following results reported. In the first part of the questionnaire, surgeons reported that they fused $81 \%$ of patients with a grade 1 spondylolisthesis. Of these, $91 \%$ of these posterior fusions were performed with instrumentation, and $51 \%$ of these instrumented posterior fusions included an interbody (Figure 1).

For the matching ACS-NSQIP data, it was identified that posterior fusion was performed for $72.7 \%$ of patients with a grade 1 spondylolisthesis. Of these, $94 \%$ of these posterior fusions were performed with instrumentation, and $62.5 \%$ of 
LSRS Survey Vs. ACS-NSQIP: Types of Posterior Fusion

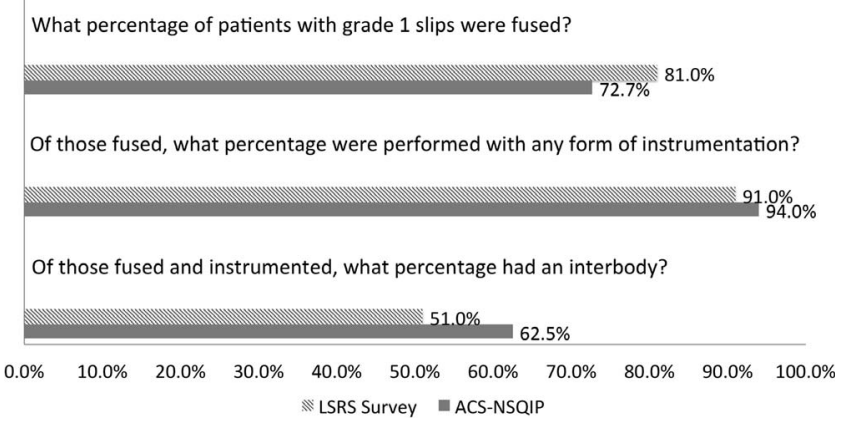

Figure 1. Types of posterior fusion used to treat lumbar degenerative spondylolisthesis. Abbreviations: LSRS, Lumbar Spine Research Society; ACS-NSQIP, American College of Surgeons National Surgical Quality Improvement Program.

these instrumented posterior fusions included an interbody (Figure 1).

For the second part of the LSRS questionnaire, questions focused on those who had undergone a primary L4-5 laminectomy and instrumented posterior fusion. Solely local autograft was used in $35 \%$ of these cases, iliac crest bone graft was harvested in $15 \%$ of these cases, and bone marrow was aspirated in $18 \%$ of these cases (Figure 2).

For the matching ACS-NSQIP data, it was identified that solely local autograft was used in $19.8 \%$ of these cases, iliac crest bone graft was harvested in $13.4 \%$ of these cases, and bone marrow was aspirated in $0.3 \%$ of these cases (Figure 2).

\section{Analysis of Perioperative Outcomes of the ACS- NSQIP Population}

\section{Patient Characteristics}

For perioperative outcomes analysis, a total of 1884 cases met the inclusion criteria. Of these, 150 $(7.96 \%)$ were uninstrumented posterior fusion cases, $622(33.01 \%)$ were instrumented posterior fusion cases, and $1112(59.02 \%)$ were instrumented posterior fusion with interbody cases (Figure 3; Table 1).

Patients treated with these 3 techniques did not differ in their distribution of gender or functional status prior to injury (Table $1 ; P \geq .05$ for each). However, these 3 techniques were statistically different in their distribution of age and modified CCI (Table $1 ; P<.001$ for each). Therefore, further analyses were adjusted for modified CCI to ensure that demographics and comorbidities did not confound the results. Age was not adjusted separately because age is already part of the calculation

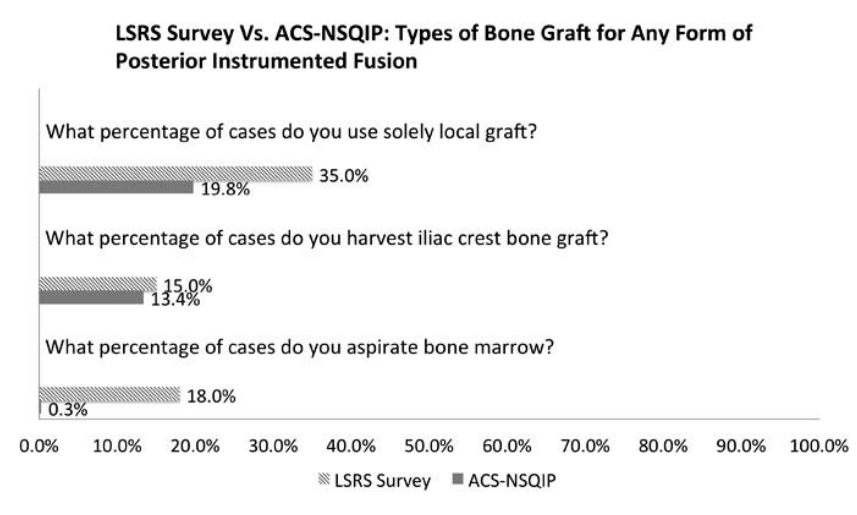

Figure 2. Types of bone graft used for instrumented posterior fusion Abbreviations: LSRS, Lumbar Spine Research Society; ACS-NSQIP, American College of Surgeons National Surgical Quality Improvement Program.

for modified CCI. The average work relative value units for uninstrumented posterior fusion is 21.22 , for instrumented posterior fusion is 20.40, and for instrumented posterior fusion with interbody is 22.18 .

\section{Perioperative Outcomes}

When controlling for modified CCI, the rate of MAE, SAE, and AAE were not statistically different between patients who underwent uninstrumented posterior fusion and instrumented posterior fusion or between those who underwent instrumented posterior fusion and instrumented posterior fusion with interbody (Tables 3 and 4; $P$ ranged from .384 to .922 ).

Mean operative times for patients who underwent uninstrumented posterior fusion and instrumented posterior fusion was statistically different (Table 3; $P=.005)$. The average difference was 22 minutes.

\section{Distribution of Posterior Fusion Techniques for Spondylolisthesis (ACS-NSQIP)}

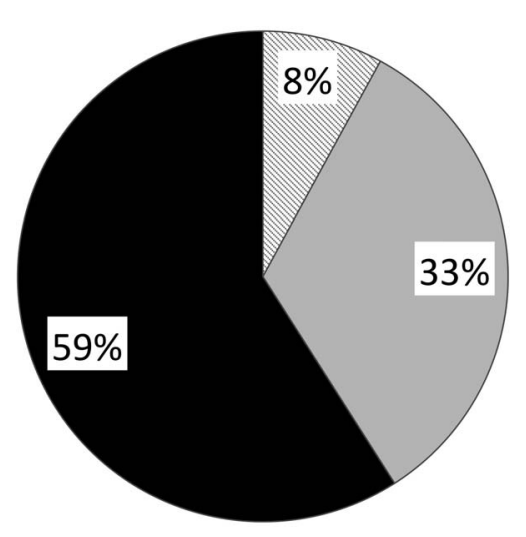

Uninstrumented Posterior Fusion

Figure 3. Distribution of posterior fusion techniques used to treat lumbar degenerative spondylolisthesis in the American College of Surgeons National Surgical Quality Improvement Program (ACS-NSQIP) population. 
Table 1. Demographic and comorbid characteristics of patients who underwent uninstrumented posterior fusion, instrumented posterior fusion, and instrumented posterior fusion with interbody.

\begin{tabular}{|c|c|c|c|c|}
\hline & \multicolumn{2}{|c|}{ Posterior Fusion, No. (\%) } & \multirow{2}{*}{$\frac{\text { Fusion With Interbody, No. (\%) }}{\text { Instrumented Posterior }}$} & \multirow[b]{2}{*}{$P$ Value } \\
\hline & Uninstrumented & Instrumented & & \\
\hline Total & $150(7.96)$ & $622(33.01)$ & $1112(59.02)$ & \multirow{9}{*}{$.001^{*}$} \\
\hline \multicolumn{4}{|l|}{ Age } & \\
\hline$<50$ & $17(11.33)$ & $79(12.70)$ & $195(17.54)$ & \\
\hline $50-54$ & $5(3.33)$ & $56(9.00)$ & $121(10.88)$ & \\
\hline $55-59$ & $17(11.33)$ & $73(11.74)$ & $167(15.02)$ & \\
\hline $60-64$ & $24(16.00)$ & $93(14.95)$ & $170(15.29)$ & \\
\hline $65-69$ & $23(15.33)$ & $109(17.52)$ & $174(15.65)$ & \\
\hline $70-74$ & $25(16.67)$ & $99(15.92)$ & $136(12.23)$ & \\
\hline$\geq 75$ & $39(26.00)$ & $113(18.17)$ & $149(13.40)$ & \\
\hline \multicolumn{4}{|l|}{ Gender } & \multirow[t]{3}{*}{.572} \\
\hline Male & $52(34.67)$ & $238(38.26)$ & $401(36.06)$ & \\
\hline Female & $98(65.33)$ & $384(61.74)$ & $711(63.94)$ & \\
\hline \multicolumn{4}{|c|}{ Functional status prior to surgery } & \multirow[t]{4}{*}{.778} \\
\hline Independent & $142(97.26)$ & $603(97.73)$ & $1085(98.19)$ & \\
\hline Partially dependent & $4(2.74)$ & $14(2.27)$ & $19(1.72)$ & \\
\hline Totally dependent & $0(0)$ & $0(0.00)$ & $1(0.09)$ & \\
\hline \multicolumn{4}{|c|}{ Modified Charlson Comorbidity Index } & \multirow[t]{6}{*}{$.001^{*}$} \\
\hline 1 & $11(7.59)$ & $50(8.32)$ & 117 (11.13) & \\
\hline 2 & $20(13.79)$ & $106(17.64)$ & $245(23.31)$ & \\
\hline 3 & $32(22.07)$ & $181(30.12)$ & $320(30.45)$ & \\
\hline 4 & $44(30.34)$ & $176(29.28)$ & $252(23.98)$ & \\
\hline$>5$ & $38(26.21)$ & $88(14.64)$ & $117(11.13)$ & \\
\hline
\end{tabular}

Bold rows are the median group.

$* \chi^{2}$ statistically significant at $P<.05$.

Mean operative times for patients who underwent instrumented posterior fusion with interbody and instrumented posterior fusion was also statistically different (Table $4 ; P<.001$ ), but again this difference was relatively small with the average difference being only 19 minutes.

LOS was not statistically different for the 3 techniques analyzed. The mean LOS for uninstrumented posterior fusion is 3.2 days, while the LOS for instrumented posterior fusion and instrumented posterior fusion with interbody was 3.4 days for both (Table 2).

The rate of readmission within 30 days of surgery was also not statistically different for the 3 techniques analyzed. The rate of readmission for uninstrumented posterior fusion, instrumented posterior fusion, and instrumented posterior fusion with interbody was $4.32 \%, 4.87 \%$, and $4.85 \%$, respectively (Table 2).

\section{DISCUSSION}

The purpose of the present study was to first obtain an understanding of the posterior surgical treatment approaches to grade 1 spondylolisthesis that spine surgeons utilize and then to evaluate the similarity of those methods with those captured by ACS-NSQIP. Secondarily, this study aimed to evaluate the short-term, general health outcomes following different posterior fusion options: uninstrumented posterior fusion, instrumented posterior fusion, and instrumented posterior fusion with interbody using the ACS-NSQIP sample.

Table 2. Number of adverse events, operative time, and length of stay for patients who underwent different posterior fusion techniques.

\begin{tabular}{|c|c|c|c|}
\hline & \multicolumn{2}{|c|}{ Posterior Fusion, No. (\%) } & \multirow{2}{*}{$\frac{\text { Fusion With Interbody, No. (\%) }}{\text { Instrumented Posterior }}$} \\
\hline & Uninstrumented & Instrumented & \\
\hline Total & $150(7.96)$ & $622(33.01)$ & $1112(59.02)$ \\
\hline Any adverse event & $31(20.67)$ & $117(18.81)$ & $192(17.27)$ \\
\hline Minor adverse event & $31(20.67)$ & $116(18.65)$ & $191(17.18)$ \\
\hline Serious adverse event & $0(0.00)$ & $5(0.80)$ & $13(1.17)$ \\
\hline Readmission & $6(4.32)$ & $28(4.87)$ & $51(4.85)$ \\
\hline Operative time, mean (SD), min & $161(85)$ & $183(76)$ & $202(78)$ \\
\hline Length of stay, mean (SD), d & $3.2(1.7)$ & $3.4(2.3)$ & $3.4(2.0)$ \\
\hline
\end{tabular}


Table 3. Uninstrumented posterior fusion relative to instrumented posterior fusion.

\begin{tabular}{|c|c|c|c|}
\hline & Relative Risk & 98.75\% Confidence Interval & $P$ Value* \\
\hline Any adverse event & 1.018 & $(0.647-1.601)$ & .922 \\
\hline Minor adverse event & 1.025 & $(0.651-1.613)$ & .892 \\
\hline Serious adverse event & $\mathrm{N} / \mathrm{A}^{* *}$ & $\mathrm{~N} / \mathrm{A}^{* *}$ & $\mathrm{~N} / \mathrm{A}^{* *}$ \\
\hline Readmission & 0.801 & $(0.267-2.401)$ & .613 \\
\hline $\begin{array}{l}\text { Operative time*** (uninstrumented [161 min] vs instrumented [183 min]) } \\
\text { (mean difference of } 22 \mathrm{~min} \text { ) }\end{array}$ & & & .005 \\
\hline $\begin{array}{l}\text { Length of stay*** (uninstrumented [3.2 days] vs. instrumented [3.4 days]) } \\
\text { (mean difference of } 0.2 \mathrm{~d} \text { ) }\end{array}$ & & & .118 \\
\hline
\end{tabular}

Bold indicates statistically significant.

*Controlled for Charlson Comorbidity Index (includes age).

**Not applicable (N/A) due to uninstrumented posterior fusion having $0 \mathrm{SAE}$ as opposed to $5 \mathrm{SAEs}$ in instrumented posterior fusion.

*** $T$-tests were used to compare these variables (significant at $P<.05$ ).

The LSRS survey component of this study was used to gain a yardstick of treatments being utilized for posterior treatments of degenerative spondylolisthesis. The response rate of greater than $60 \%$ was favorable in comparison with other physician survey studies. $^{29,30}$ The most surprising finding from our perspective was the high rate of interbody fusions $(51.0 \%)$ for posterior instrumented cases.

Given the high rate of reported interbody fusions for instrumented posterior surgeries for degenerative spondylolisthesis, we proceeded to evaluate this trend in the ACS-NSQIP database. This revealed remarkably similar trends. The ACS-NSQIP study found that $72.7 \%$ cases of posterior surgery for degenerative spondylolisthesis were fused, of those $94 \%$ were instrumented, and of those $62.5 \%$ had interbody fusion performed.

Overall, it is clear from the data sets analyzed that most posterior surgeries for degenerative spondylolisthesis do employ instrumented posterior fusion. This is well supported by recent studies such as SPORT. ${ }^{5-7}$ Further, the majority of those use interbody devices. These findings support past studies that have reported increasing usage of interbody fusion. ${ }^{2}$ This is of particular interest, as there is no robust data to support clinical superiority of adding interbody devices to instrumented posterior fusion. ${ }^{10,15,31,32}$ It might be that this is being driven by the rise in popularity of minimally invasive surgery (MIS) that requires the interbody space for a surface area for fusion. Unfortunately, we cannot determine the percent of cases that were done with MIS techniques using the data sets employed here.

In terms of bone grafts utilized for these surgeries, the utilization of iliac crest autograft was reported similarly for LSRS survey as identified in ACS-NSQIP (15\% and $13.4 \%$, respectively). On the other hand, greater differences were seen for local autograft only (35\% vs $19.8 \%$, respectively) and bone marrow aspirate $(18 \%$ and $0.3 \%$, respectively). It is hypothesized that this is due to coding limitation for these low reimbursement codes in ACS-NSQIP, but this cannot be confirmed.

The low rate of utilization of iliac crest autograft is of interest. Although this has long been considered the "gold standard" grafting material, it is clear that trends have shifted away from its use and it is only used in the minority of cases. This is presumably related to the concerns over related morbidity. 33

The variations in posterior surgical techniques used for lumbar degenerative spondylolisthesis lead us to want to compare the perioperative outcomes of treatment options. Clearly if differences in morbidity and postoperative course were noted,

Table 4. Instrumented posterior fusion with interbody relative to instrumented posterior fusion.

\begin{tabular}{|c|c|c|c|}
\hline & Relative Risk & 98.75\% Confidence Interval & $P$ Value* \\
\hline Any adverse event & 0.950 & $(0.729-1.240)$ & .633 \\
\hline Minor adverse event & 0.955 & $(0.731-1.247)$ & .663 \\
\hline Serious adverse event & 1.598 & $(0.416-6.132)$ & .384 \\
\hline Readmission & 1.053 & $(0.588-1.886)$ & .825 \\
\hline $\begin{array}{l}\text { Operative time** (with interbody [202 } \mathrm{min}] \text { vs without interbody [183 } \mathrm{min}] \text { ) } \\
\text { (mean difference of } 19 \mathrm{~min} \text { ) }\end{array}$ & & & $<.001$ \\
\hline $\begin{array}{l}\text { Length of stay** (with interbody [3.4 d] vs without interbody [3.4 d]) } \\
\quad(\text { mean difference of } 0 \mathrm{~d})\end{array}$ & & & .554 \\
\hline
\end{tabular}

Bold indicates statistically significant.

*Controlled for Charlson Comorbidity Index (includes age).

** $T$-tests were used to compare these variables (significant at $P<.05$ ). 
this might argue for or against certain surgical options. Perioperative adverse events were analyzed in ACS-NSQIP for this population and, when controlling for CCI, no significant differences were identified for the occurrence of adverse events within 30 days of the procedure, hospital LOS, or readmission for the posterior techniques used to address lumbar degenerative spondylolisthesis studied here. These results validated our hypothesis and correlated with previous studies that reported similar short-term complications between uninstrumented fusion, instrumented fusion, and instrumented fusion with interbody in a different patient sample. $^{2}$

This observation makes it clear that perioperative adverse events are not the driver by which one can differentiate the surgical procedures evaluated for addressing lumbar degenerative spondylolisthesis. The driver should therefore be long-term outcomes, patient choice, or surgeon preference. While our data cannot conclusively determine if revenues or commercialization/marketing from instrumentation companies affect surgical decision-making regarding which fusion technique to utilize, we did demonstrate somewhat similar work relative value units for the 3 fusion techniques in our patient cohort. It is the authors' opinion that surgeons should always have patients' best interests in mind when making any treatment decisions.

It is of note there were statistically significant differences in operative time. Compared to uninstrumented posterior fusion, instrumented posterior fusion took an average of 22 minutes of additional time $(P=.005)$. Compared to instrumented posterior fusion, instrumented posterior fusion with interbody took an average of 19 minutes of additional time $(P<.001)$. Although operative time has been associated with an increased risk of adverse events in other studies, ${ }^{34,35}$ the differences were not associated with different perioperative morbidity in the current study. Thus, the clinical significance of these relatively small differences is thought not to be great in this setting.

This paper has clear strengths. The most current observed practice trends to date were confirmed from 2 sources (LSRS survey and ACS-NSQIP). Further, the large and validated ACS-NSQIP population was able to evaluate the perioperative outcomes of posterior surgical techniques used to address lumbar degenerative spondylolisthesis.
There are limitations to the current study. As with any survey study, the LSRS study is prone to surgeon recall bias. That said, that is why the current study was supplemented with ACS-NSQIP data. With regard to the evaluation of perioperative morbidity, the ACS-NSQIP population does not contain spine specific outcome variables that might be of clinical significance such as characterizations of surgical pathology and neurologic injury. Further, the ACS-NSQIP database does not record spine structural variables such as facet orientation, dynamic instability, and coronal or sagittal deformity. Thus, these potentially important variables and certain subsets of patients could not be analyzed. The methodology of the current study also inherently poses limitations on studying subsets of patients with degenerative spondylolisthesis. National population data and recall questionnaires often aggregate patients and only allow ballpark responses. Thus, treatment $\mid$ utilization trends may be different among subsets of patients with degenerative spondylolisthesis, but the methodology of the current study is not suited to detect these differences. In addition, this study only evaluated posterior fusion approaches (anterior and lateral approaches may be considered for lumbar degenerative spondylolisthesis, but these were not evaluated in the current paper). Lastly, the ACS-NSQIP database only records data through the 30th postoperative day, so longer-term outcomes could not be evaluated in the current study.

In summary, there are significant variations in the surgical management of lumbar degenerative spondylolisthesis. Of the posterior approaches used to address this pathology, the data presented here demonstrate that most cases used to address this pathology include posterior instrumentation and the majority is with interbody fusion. The lack of differences in general health adverse events, hospital LOS, and readmission rates between these techniques suggest that the decision for the appropriate intervention should focus on other metrics such as surgeon preference, patient experience, cost-benefit considerations, and longer-term outcome variables. In the future, large national databases should perhaps consider recording these variables so meaningful analyses could be undertaken.

\section{ACKNOWLEDGMENTS}

The authors have no ownerships, patents, or participations with entities whose products or 
category of products are mentioned in the current manuscript.

Our institutional review board granted an exemption for studies using this data set because all data are deidentified and anonymous.

\section{REFERENCES}

1. Sengupta DK, Herkowitz HN. Degenerative spondylolisthesis: review of current trends and controversies. Spine (Phila Pa 1976). 2005;30(6 suppl):S71-S81.

2. Kepler CK, Vaccaro AR, Hilibrand AS, et al. National trends in the use of fusion techniques to treat degenerative spondylolisthesis. Spine (Phila Pa 1976). 2014;39(19):15841589.

3. Lombardi JS, Wiltse LL, Reynolds J, Widell EH, Spencer C 3rd. Treatment of degenerative spondylolisthesis. Spine (Phila Pa 1976). 1985;10(9):821-827.

4. Schroeder GD, Kepler CK, Kurd MF, et al. Rationale for the surgical treatment of lumbar degenerative spondylolisthesis. Spine (Phila Pa 1976). 2015;40(21):E1161-E1166.

5. Weinstein JN, Lurie JD, Tosteson TD, et al. Surgical versus nonsurgical treatment for lumbar degenerative spondylolisthesis. N Engl J Med. 2007;356(22):2257-2270.

6. Weinstein JN, Lurie JD, Tosteson TD, et al. Surgical compared with nonoperative treatment for lumbar degenerative spondylolisthesis. four-year results in the Spine Patient Outcomes Research Trial (SPORT) randomized and observational cohorts. J Bone Joint Surg Am. 2009;91(6):1295-1304.

7. Rihn JA, Hilibrand AS, Zhao W, et al. Effectiveness of surgery for lumbar stenosis and degenerative spondylolisthesis in the octogenarian population: analysis of the Spine Patient Outcomes Research Trial (SPORT) data. J Bone Joint Surg Am. 2015;97(3):177-185.

8. Herkowitz HN, Kurz LT. Degenerative lumbar spondylolisthesis with spinal stenosis. A prospective study comparing decompression with decompression and intertransverse process arthrodesis. J Bone Joint Surg Am. 1991;73(6):802-808.

9. Fischgrund JS, Mackay M, Herkowitz HN, Brower R, Montgomery DM, Kurz LT. 1997 Volvo Award winner in clinical studies. Degenerative lumbar spondylolisthesis with spinal stenosis: a prospective, randomized study comparing decompressive laminectomy and arthrodesis with and without spinal instrumentation. Spine (Phila Pa 1976). 1997;22(24):2807-2812.

10. McAnany SJ, Baird EO, Qureshi SA, Hecht AC, Heller JG, Anderson PA. Posterolateral fusion versus interbody fusion for degenerative spondylolisthesis: a systematic review and meta-analysis. Spine (Phila Pa 1976). 2016;41(23):E1407E1414.

11. Shah RR, Mohammed S, Saifuddin A, Taylor BA. Radiologic evaluation of adjacent superior segment facet joint violation following transpedicular instrumentation of the lumbar spine. Spine (Phila Pa 1976). 2003;28(3):272-275.

12. Lad SP, Babu R, Ugiliweneza B, Patil CG, Boakye M. Surgery for spinal stenosis: long-term reoperation rates, health care cost, and impact of instrumentation. Spine (Phila $\mathrm{Pa}$ 1976). 2014;39(12):978-987.
13. Koreckij TD, Fischgrund JS. Degenerative spondylolisthesis. J Spinal Disord Tech. 2015;28(7):236-241.

14. Ha KY, Na KH, Shin JH, Kim KW. Comparison of posterolateral fusion with and without additional posterior lumbar interbody fusion for degenerative lumbar spondylolisthesis. J Spinal Disord Tech. 2008;21(4):229-234.

15. Gottschalk MB, Premkumar A, Sweeney K, et al. Posterolateral lumbar arthrodesis with and without interbody arthrodesis for 14-15 degenerative spondylolisthesis: a comparative value analysis. Spine (Phila Pa 1976). 2015;40(12):917925.

16. Bovonratwet P, Nelson SJ, Bellamkonda K, et al. Similar 30-day complications for septic knee arthritis treated with arthrotomy or arthroscopy: an american college of surgeons national surgical quality improvement program analysis Arthroscopy. 2018;34(1):213-219.

17. American College of Surgeons National Surgical Quality Improvement Program. User guide for the 2013 ACS NSQIP participant use data file. http://site.acsnsqip.org/wp-content/ uploads/2014/11/ACS_NSQIP_PUF_User_Guide_2013.pdf. Accessed June 5, 2016.

18. Khuri SF. The NSQIP: a new frontier in surgery. Surgery. 2005;138(5):837-843.

19. Schilling PL, Hallstrom BR, Birkmeyer JD, Carpenter JE. Prioritizing perioperative quality improvement in orthopaedic surgery. J Bone Joint Surg Am. 2010;92(9):1884-1889.

20. Charlson ME, Pompei P, Ales KL, MacKenzie CR. A new method of classifying prognostic comorbidity in longitudinal studies: development and validation. J Chronic Dis. 1987;40(5):373-383.

21. Ehlert BA, Nelson JT, Goettler CE, et al. Examining the myth of the "July Phenomenon" in surgical patients. Surgery. 2011;150(2):332-338.

22. Sundararajan V, Henderson T, Perry C, Muggivan A, Quan H, Ghali WA. New ICD-10 version of the Charlson comorbidity index predicted in-hospital mortality. J Clin Epidemiol. 2004;57(12):1288-1294.

23. D'Hoore W, Bouckaert A, Tilquin C. Practical considerations on the use of the Charlson comorbidity index with administrative data bases. $J$ Clin Epidemiol. 1996;49(12):1429-1433.

24. Lukasiewicz AM, Basques BA, Bohl DD, Webb ML, Samuel AM, Grauer JN. Myelopathy is associated with increased all-cause morbidity and mortality following anterior cervical discectomy and fusion: a study of 5256 patients in American College of Surgeons National Surgical Quality Improvement Program (ACS-NSQIP). Spine (Phila Pa 1976). 2015;40(7):443-449.

25. Bohl DD, Fu MC, Golinvaux NS, Basques BA, Gruskay JA, Grauer JN. The "July effect" in primary total hip and knee arthroplasty: analysis of 21,434 cases from the ACS-NSQIP database. J Arthroplasty. 2014;29(7):1332-1338.

26. Bohl DD, Ahn J, Lukasiewicz AM, et al. Severity weighting of postoperative adverse events in orthopaedic surgery. Am J Orthop (Belle Mead NJ). 2017;46(6):E235-E243.

27. Zou G. A modified poisson regression approach to prospective studies with binary data. Am $J$ Epidemiol. 2004;159(7):702-706.

28. Dunn OJ. Multiple comparisons among means. $J \mathrm{Am}$ Stat Assoc. 1961;56(293):52-64.

29. Cummings SM, Savitz LA, Konrad TR. Reported 
response rates to mailed physician questionnaires. Health Serv Res. 2001;35(6):1347-1355.

30. Asch DA, Jedrziewski MK, Christakis NA. Response rates to mail surveys published in medical journals. $J$ Clin Epidemiol. 1997;50(10):1129-1136.

31. Abdu WA, Lurie JD, Spratt KF, et al. Degenerative spondylolisthesis: does fusion method influence outcome? Fouryear results of the Spine Patient Outcomes Research Trial. Spine (Phila Pa 1976). 2009;34(21):2351-2360.

32. Challier V, Boissiere L, Obeid I, et al. One-level lumbar degenerative spondylolisthesis and posterior approach. Is transforaminal lateral interbody fusion mandatory? A randomized controlled trial with two-year follow-up. Spine (Phila $\mathrm{Pa}$ 1976). 2016;42(8):531-539.

33. Dimitriou R, Mataliotakis GI, Angoules AG, Kanakaris NK, Giannoudis PV. Complications following autologous bone graft harvesting from the iliac crest and using the RIA: a systematic review. Injury. 2011;42(suppl 2):S3-S15.

34. Basques BA, Ibe I, Samuel AM, et al. Predicting postoperative morbidity and readmission for revision posterior lumbar fusion. Clin Spine Surg. 2017;30(6):E770-E775.

35. Basques BA, Chung SH, Lukasiewicz AM, et al. Predicting short-term morbidity in patients undergoing posterior spinal fusion for neuromuscular scoliosis. Spine (Phila Pa 1976). 2015;40(24):1910-1917.

\section{APPENDIX}

\section{Lumbar Spine Research Society Questionnaire}

\section{Lumbar Fusion and Bone Grafting: Practices and Beliefs*}

Introduction: Lumbar degenerative spondylolisthesis is the most common diagnosis leading to spinal fusion surgery in the United States. Over the past several years, marked changes in practice patterns have occurred in terms of surgical technique and use of bone graft alternatives. The purpose of this survey is to determine prevalent practice patterns and beliefs among a select group of leading lumbar spine specialists regarding fusion surgery and graft materials in this patient population.
The following questions refer to your treatment of patients with degenerative spondylolisthesis and stenosis who are considered appropriate candidates for surgery (primary, nonrevision, single level):

1. Over the past year, what percentage of patients with a grade 1 slip did you fuse?

1a. What percentage of these fusions were performed with instrumentation?

1b. What percentage of these were performed with an interbody fusion?

The following questions refer to your "average" patient with a grade 1 slip undergoing a primary L45 laminectomy and posterior instrumented fusion:

1. In what percentage of instrumented cases do you use solely local graft without any additional material or extenders?

2. In what percentage of cases do you harvest iliac crest bone graft?

3. In what percentage of cases do you aspirate bone marrow?

*The presented form is a subset of the full questionnaire focusing on the questions used for the current study.

Corresponding Author: Jonathan N. Grauer, MD, Department of Orthopaedics and Rehabilitation, Yale University School of Medicine, 47 College St, New Haven, CT 06520. Phone: (203) 737-7463 ; Fax: (203) 785-7132; Email: jonathan. grauer@yale.edu.

Published 30 April 2019

This manuscript is generously published free of charge by ISASS, the International Society for the Advancement of Spine Surgery. Copyright (C) 2019 ISASS. To see more or order reprints or permissions, see http://ijssurgery.com. 